\title{
Contributors to fluxgate magnetic noise in permalloy foils including a potential new copper alloy regime
}

\author{
David M. Miles ${ }^{1}$, Richard Dvorsky ${ }^{1}$, Kenton Greene ${ }^{1}$, Christian T. Hansen ${ }^{1}$, B. Barry Narod ${ }^{2}$, and Michael D. Webb ${ }^{1}$ \\ ${ }^{1}$ Department of Physics and Astronomy, University of Iowa, Iowa City, IA 52242, USA \\ ${ }^{2}$ Department of Earth, Ocean and Atmospheric Sciences, University of British Columbia, Vancouver, Canada
}

Correspondence: David M. Miles (david-miles@uiowa.edu)

Received: 7 November 2021 - Discussion started: 12 November 2021

Revised: 31 January 2022 - Accepted: 1 February 2022 - Published: 3 March 2022

\begin{abstract}
Fluxgate magnetometers provide sensitive and stable measurements of the static and low-frequency vector magnetic field. Fluxgates form a magnetic field measurement by periodically saturating a ferromagnetic core and the intrinsic magnetic noise of this material can determine the noise floor of the instrument. We present the results of an empirical experiment to understand the physical parameters that influence the intrinsic magnetic noise of fluxgate cores. We compare two permalloy alloys - the historical standard $6 \%$ molybdenum alloy and a new $28 \%$ copper alloy. We examine the influence of geometry using the historical standard 1 in. diameter spiral-wound ring core and a new stacked washer racetrack design. We evaluate the influence of material thickness by comparing 100 and $50 \mu \mathrm{m}$ foils. Finally, we investigate heat treatments in terms of temperature and ramp rate and their role in both grain size and magnetic noise. The results of these experiments suggest that thinner foils, potentially comprising the copper alloy, manufactured into continuous racetrack geometry washers may provide excellent performance in fluxgate sensors.
\end{abstract}

\section{Introduction}

Fluxgate magnetometers (Fornacon et al., 1999; Primdahl, 1979; Snare, 1998) provide sensitive and stable measurements of the local DC and low-frequency magnetic field and have a variety of applications ranging from geophysics, space-physics and space-weather monitoring, to marine and military sensing. The noise floor of a fluxgate is typically limited by the intrinsic magnetic noise of a ferromagnetic core that is periodically driven into magnetic saturation to modulate the local magnetic field. Much of the early work developing low-noise cores was carried out in the 1960s for military applications (e.g., Scanlon, 1966) and is not available in the scholarly literature. This work by the US Naval Surface Weapons Center (NSWC) White Oak (now a Department of Agriculture facility) and Infinetics Inc. (Scarzello et al., 2001) resulted in the standard S1000 fluxgate core, a $1 \mathrm{in}$. ring core manufactured from a thin $(3$ or $12 \mu \mathrm{m})$ foil of $6 \%$ molybdenum permalloy with noise ranging from $\sim 4$ to $\sim 20 \mathrm{pT} / \sqrt{ } \mathrm{Hz}$ at $1 \mathrm{~Hz}$. Müller (1998) and Musmann (2010) both describe more recent efforts achieving $<5$ pT noise using a $20 \mu \mathrm{m}$ foil for similar permalloy. However, none of these efforts provide enough details for the manufacturing process to be understood unambiguously or to fully understand the effect of various design choices on the performance of the resulting fluxgate core.

Recent results from Narod (2014) established a theoretical framework for the origin of magnetic noise and magnetic hysteresis in permalloy foils. An initial effort (Miles et al., 2019) demonstrated and documented a preliminary manufacturing process for low-noise $(<10 \mathrm{pT}) 1 \mathrm{in}$. geometry ring cores. This study expands on that work by examining the influence of foil thickness, heat treatment, geometry, and the permalloy alloy with the goal of consistently producing lower-noise and lower-power fluxgate cores.

We present the results of an initial parameter sweep comparing the traditional $6 \%$ molybdenum alloy to a new $28 \%$ copper alloy. Each alloy is tested at both 100 and $50 \mu \mathrm{m}$ foil thicknesses with thinner foils planned to be explored as our manufacturing capability improves. We explore the effect of the heat treatment used to optimize magnetic noise by exploring six temperatures spanning 1000 to $1250^{\circ} \mathrm{C}$. Flux- 
gate cores are manufactured in two geometries - the standard spiral-wound $1 \mathrm{in}$. ring core and a new $6.45 \mathrm{~mm} \times 31.45 \mathrm{~mm}$ racetrack geometry using continuous foil washers. We explore the relationship between number of foil layers and both magnetic noise and power consumption. We examine the effect of an additional sub-Curie heat treatment at $100^{\circ} \mathrm{C}$ on the intrinsic magnetic noise of the cores. We have standardized using three layers of foil for most tests in both core geometries to simplify manufacturing. Consequently, we are not expecting exceptional noise performance in these rings; rather, we want to understand trends and to optimize the manufacturing process.

We hypothesize that magnetic noise is influenced by the grain size developed in the permalloy in relation to the thickness of the foil. Specifically, that complete primary recrystallization will result in lowering magnetic noise, whereas secondary recrystallization will result in higher magnetic noise. We manufactured test coupons for every combination of material, thickness, and heat treatment and characterized their grain size distribution to begin exploring this relationship.

\section{Construction of candidate cores}

All cores were manufactured from scratch at the University of Iowa. All permalloy alloys were melted and processed in house and all bobbins were manufactured and assembled based on in-house designs.

\subsection{Production of permalloy alloy}

The fluxgate cores described here were based on permalloy manufactured at the University of Iowa. Casting small batches of permalloy in-house allows us to more easily and cost effectively explore new metallurgy such as the copper alloy described below. High-purity source powders were combined by ratio of weight, shaken to mix, and gently packed into an Alumina crucible (Fig. 1a). The crucible was placed in the process furnace under a slow purge of a reducing atmosphere of $10 \%$ hydrogen diluted in argon. The process furnace ramped from room temperature to $1550^{\circ} \mathrm{C}$ at $300^{\circ} \mathrm{Ch}^{-1}$, held for a $1 \mathrm{~h}$ duration, and then returned to room temperature at $300^{\circ} \mathrm{Ch}^{-1}$. The base powders combined to form a single uniform ingot (Fig. 1b) - the higher melting point molybdenum dissolving in the other liquid metals (e.g., Sene and Motta, 2013). Small cavities in the ingot were sometimes observed in the face contacting the crucible. A vacuum purge while the furnace was at $1550^{\circ} \mathrm{C}$ did not significantly reduce cavity formation.

The ingots were then homogenized for $7 \mathrm{~d}$ at $1100^{\circ} \mathrm{C}$ under a slow purge of the same reducing atmosphere. A hydraulic press was used to flatten the ingots to $\sim 3 \mathrm{~mm}$ thickness (Fig. 1c) after which they were machined roughly rectangular. Successive cold rolling reduced the ingot down to a $100 \mu \mathrm{m}$ foil (Fig. 1d) in $\sim 130$ passes. An additional $\sim 10$

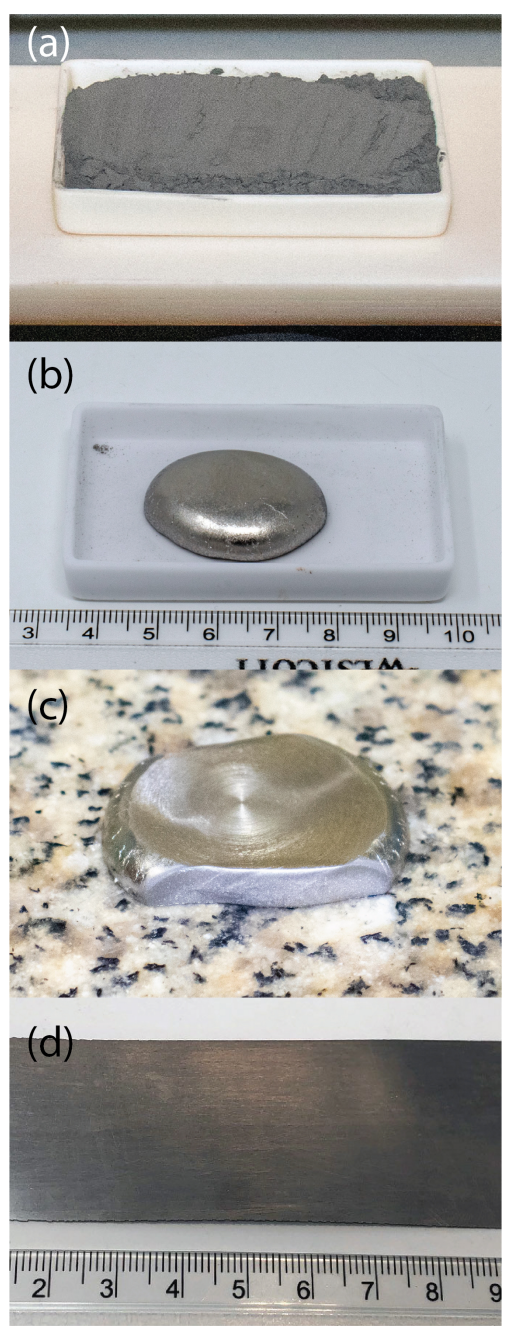

Figure 1. Permalloy was manufactured starting from high-purity source powders that are mixed (a) and then melted together (b) via $1 \mathrm{~h}$ at $1550^{\circ} \mathrm{C}$. The resulting ingot is flattened in a hydraulic press (c), machined rectangular, and successively cold rolled into 100 and then $50 \mu \mathrm{m}$ foil (d).

passes further reduced a subset of the foil to $50 \mu \mathrm{m}$ which is the present limit of our rolling mill capability.

\subsection{6-81 molybdenum alloy [6-81 Mo]}

Half of the fluxgate cores manufactured for this experiment were constructed from an alloy similar to the historical 6-81 Mo permalloy (English and Chin, 1967; Odani, 1964; Pfeifer, 1966; Pfeifer and Boll, 1969; Scanlon, 1966) combined by weight from $6 \%$ molybdenum, $81.3 \%$ nickel, and the remainder iron. The 6-81 alloy was first proposed for fluxgate use by Gordon et al. (1968) and has been used by several groups worldwide including Infinetics Inc., Müller et al. (1998), and Musmann (2010). The historical 6-81 alloys included $\sim 0.5 \%$ manganese which is a common alloy additive to improve hot working, notionally by binding to sul- 
fur contaminants. The historical 6-81 melts were hot rolled (Gordon and others, 1968), but our own melts were not, and therefore we omitted manganese.

\section{$2.3 \quad 28-62$ copper alloy $[28-62 \mathrm{Cu}]$}

The second half of the fluxgate cores shown here were manufactured using a ferromagnetic alloy, mentioned in Narod (2014), that we hypothesized has potential to produce highquality fluxgate cores. This $28-62 \mathrm{Cu}$ alloy was combined by weight from $28 \%$ copper, $62 \%$ nickel, and the remainder iron. This ratio was derived from the theoretical framework established by Narod (2014) and prior experimental results from von Auwers and Neumann (1935), who explored a wide range of iron-nickel-copper alloys searching for high initial permeability. Von Auwers and Neumann (1935) presented their work in a special print from the scientific publications of the Siemens factory that was not widely circulated to the public.

The choice of 28-62 Cu for a first trial copper alloy resulted from an examination of Figs. 8, 11, and 13 from von Auwers and Neuman (1935), which graph magnetic property data for a large range of iron-nickel-copper alloys, for a heat treatment process roughly similar to the ones used in our own experimental efforts. According to these old graphs, 28-62 Cu simultaneously maximizes initial magnetic permeability and minimizes magnetostriction. These are both indicators for minimum magnetic anisotropy, which according to Narod (2014) leads to the reduction of magnetostatic energy in the material and which is a direct diagnostic for improved magnetic noise. It is also the case that $28-62 \mathrm{Cu}$ has expected magnetic saturation induction, Bs, like that of 6-81 Mo permalloy. Both theoretical calculations in Narod (2014) and Bs data graphed in von Auwers and Neuman (1935) lead to that result. For both experimental observation and theoretical reasons Bs is a lead indicator for magnetic noise (Narod et al., 1985; Mussmann, 2010; Narod, 2014). 28-62 Cu's expected lower Bs of 0.5-0.6 T should be advantageous.

\subsection{Ring-core and racetrack variants}

Two styles of fluxgate cores were manufactured to explore the impact of geometry. The classic Infinetics S1000 1 in. ring-core geometry was used as the standard design. We also manufactured cores in an alternative racetrack geometry (Gordon et al., 1965; Hinnrichs et al., 2000, 2001; Ripka, $1990,1993,2000)$ that combines the symmetry and closed flux path of a ring core with the high single-axis geometric gain of a parallel rod core. The racetrack geometry also allowed us to experiment with several design changes that were intended to increase reproducibility and reduce power consumptions.

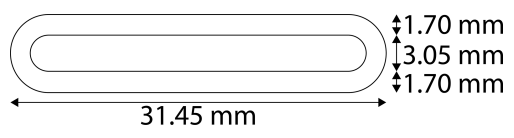

Figure 2. Dimensions of the machined ferromagnetic foil used in the racetrack core.

\subsection{1 in. ring cores}

The 1 in. ring cores were manufactured following the description in Miles et al. (2019) as shown in Fig. 3 (panels 1a1d). Permalloy foil was sheared into $1.57 \mathrm{~mm}$ wide strips sufficiently long for three layers. Each strip was spot welded to the Inconel bobbin, dilute milk of magnesia was applied and dried, and the foil was wound three times and spot welded to itself aligned to the start point. The assembled ring cores were heat treated with variations of the standard process heat treatment as described below. The ring cores were then insulated with Mylar tape, toroidal drive windings of AWG 32 wire were applied, and the leads were terminated in a twisted pair.

\subsection{Racetrack cores}

The racetrack design makes several fundamental changes beyond the gross geometry of the core assembly as shown in Fig. 3 (panels $2 \mathrm{a}-2 \mathrm{~d}$ ). The permalloy foil was cut to $\sim 5 \mathrm{~cm}$ length, stacked, drilled, and secured in a tight bundle. A computer numerical control (CNC) mill was used to machine continuous $6.45 \mathrm{~mm}$ wide by $31.45 \mathrm{~mm}$ long racetrack foil washers (Fig. 2). The track width was machined to $1.70 \mathrm{~mm}$. The gap was sized to comfortably accommodate hand winding of a toroidal drive winding.

No insulating coating was applied; rather, the racetrack washers were placed in the furnace bare and heat treated using variations of the standard process heat treatment as described below, prior to being assembled into a core. Heattreated foils were then stacked into a non-conductive plastic bobbin (Delrin for prototypes, $30 \%$ glass filled PEEK for production) interleaved with insulating layers of Kapton film of the same geometry. A plastic lid closed the core and supports a quasi-toroidal drive of AWG 32 wire. Production cores have the foil wet set into a polymer to prevent the foil layers from moving during the magnetizing drive pulses. We are investigating foil movement as a source of long-term offset shifts.

The stacked foil washers remove the need to spot weld the ferromagnetic element, as is done in traditional spiralwound sensors, avoiding the heat-affected area around the weld and the associated unpredictable magnetic properties. Heat treating the foil washers individually removes the risk of undesired welding between layers and between the foil and the standard metal Inconel bobbin that can cause unintended shorting. This process also eliminates the differential strains between Inconel and permalloy, that invariably hap- 


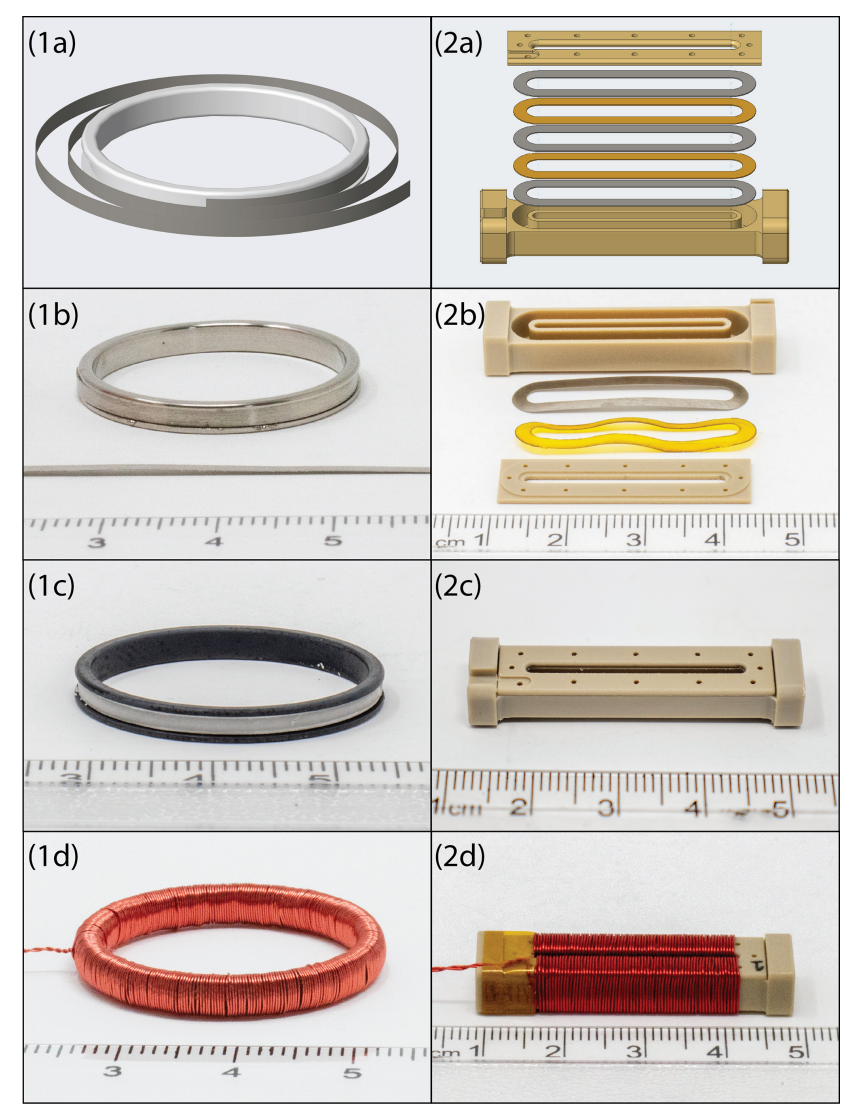

Figure 3. Assembly of a 1 in. ring core illustrated by (1a) render of principle components, (1b) photo of main components, (1c) assembled ring core prior to application of drive winding, and (1d) wound ring core. Panels (2a)-(2d) show the same steps for the racetrack geometry core.

pens when cooling the assembly from $\sim 1100^{\circ} \mathrm{C}$ to room temperature. The racetrack geometry aligns ferromagnetic mass on one axis, potentially producing lower noise; however, the racetrack geometry cannot be double wound like a ring core to sample two orthogonal components. The quasitoroidal drive windings are time-consuming to apply; however, some literature (e.g., Janosek, 2017) suggests that the closed flux path of the racetrack may reduce magnetic noise, stray fields, and offsets error compared to traditional parallel rod sensors by avoiding the presence of an unsaturated or weakly saturated end region (e.g., Moldovanu et al., 2000), and this will be examined in future work.

\subsection{Heat treatment}

The heat treatments used here are adapted from the profile (Fig. 4a) of Miles et al. (2019) which are, in turn, based loosely on a description given by Gordon et al. (1968). The heat treatment starts with the ferromagnetic material at room temperature (A) and comprises four steps: rapid heating (B) of the ferromagnetic material by insertion into the pre-heated furnace, a fixed length dwell (B-C), ramping down to the upper limit of the critical ordering range $(\mathrm{C}-\mathrm{D})$, and finally a slow ramp to room temperature (D-E). This profile follows the theory of Narod (2014) with the goal of developing the largest possible grains in the given thickness of the permalloy foil, enhancing primary recrystallization through rapid heating, and suppressing secondary recrystallization by rapidly cooling to the disordering range.

The furnace was preheated to the dwell temperature at $300^{\circ} \mathrm{C}$ per hour, the fastest rate suggested by the manufacturer to avoid cracking the Alumina work tube by thermal shock. Ramp (C-D) was completed at $-300^{\circ} \mathrm{C}$ per hour for the same reason. Ramp (D-E) was completed at $-35^{\circ} \mathrm{C}$ per hour as used by Gordon et al. (1968). The transition point (D) was set at $600^{\circ} \mathrm{C}$ at the upper limit of the critical ordering range for 6-81 permalloy defined by Gordon et al. (1968). To explore the effect of the heat treatment, we standardized on a $4 \mathrm{~h}$ dwell at temperatures ranging from 1000 to $1250^{\circ} \mathrm{C}$ as shown in Fig. 4b. The transient dip in the dwell temperature occurs when the room temperature permalloy, and the boat used to transport it, are slid into the hot zone of the furnace. All heat treatments were completed under a continuous slow purge of a reducing atmosphere of $10 \%$ hydrogen diluted in argon.

\section{Core characterization}

A common electronics package was used to drive each ring core, measure the power consumption required, and characterize its power spectral density noise floor. In addition, foil coupons for each alloy and thickness were included in each heat treatment so that the grain size could be characterized optically.

\subsection{Fluxgate core characterization setup}

The various fluxgate cores were characterized using a process similar to that described in Miles et al. (2019). A common, single-axis electronics package was used to drive and sample each fluxgate core. The $1 \mathrm{in}$. ring cores were paired with a rectangular solenoidal sense winding similar to that used in Wallis et al. (2015), while the racetrack cores were paired with a tubular solenoidal sense coil matching their geometry (Fig. 5). Fixturing allowed these sense windings to be aligned with a large solenoid, used to generate a calibration magnetic field, mounted within a five-layer MuMETAL shield.

A common electronics package was used to drive all cores using $\pm 7.5 \mathrm{~V}$ at $5.0 \mathrm{kHz}$. Both legs of the drive circuit used $1850 \mu \mathrm{H}$ series inductors to create the resonant drive condition. For each core, the shunt capacitance was increased until symmetric current pulses were observed through the drive winding showing that minimum resonance had been 

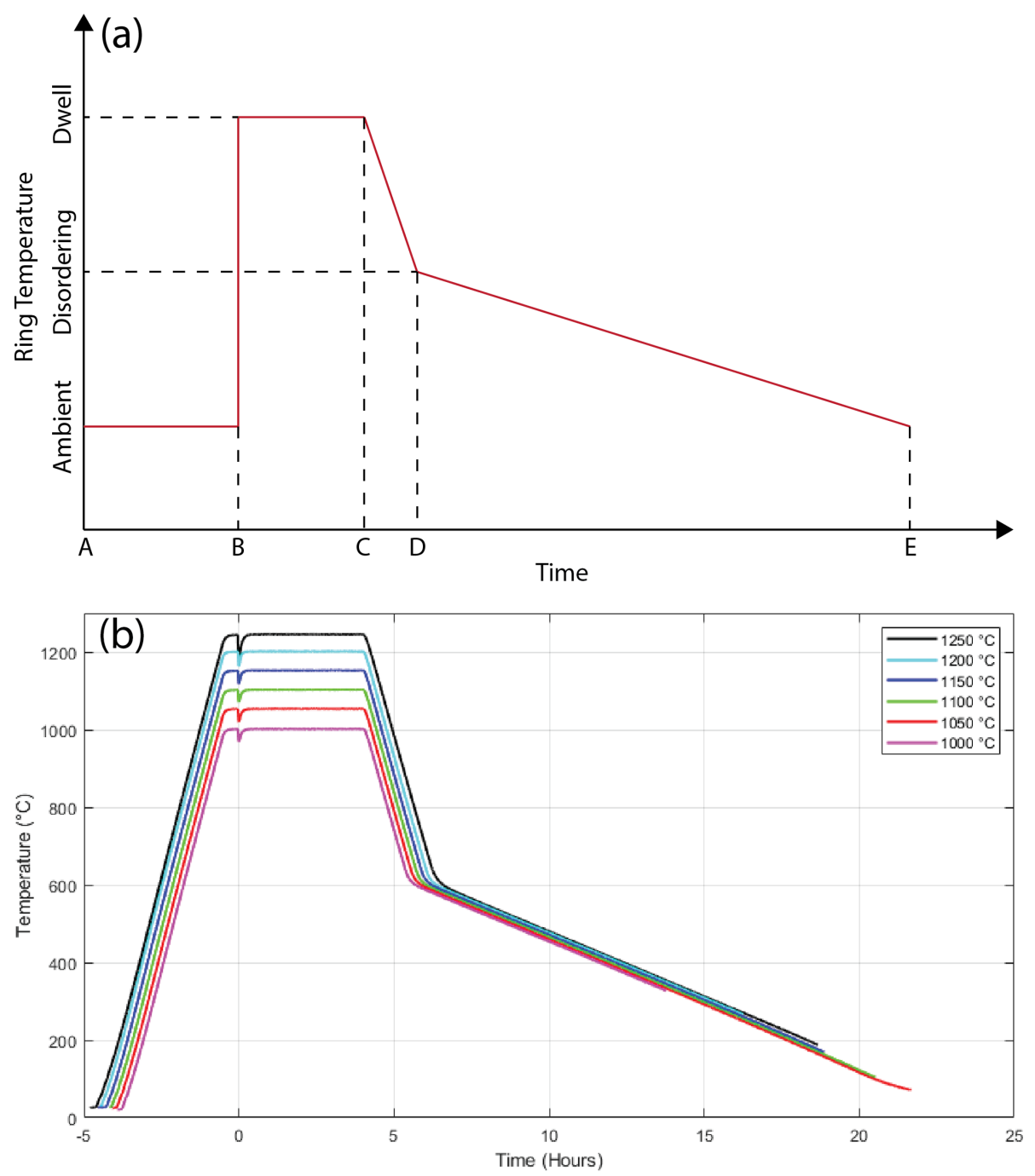

Figure 4. (a) Illustrative ideal heat treatment - adapted from Miles et al. (2019). (b) Real-world heat treatments. Time is normalized to the point when the material was hot loaded into the furnace indicated by the temperature dip.

achieved (Fig. 6a) - then $50 \%$ additional capacitance was added.

A common shorted-coil topology pre-amplifier was used for both sense windings. Several cores coupled large amounts of the fundamental frequency (1F) current waveform into the output of the sensor (Fig. 6b). To avoid electrical clipping of the pre-amplifier we standardized on a common $555 \Omega$ feedback resistance. Although low, this accommodated all the cores shown in this experiment and provided a common comparison. A high-Q bandpass filter at the $10.0 \mathrm{kHz} 2 \mathrm{~F}$ frequency acted as the anti-aliasing filter and provided $37 \mathrm{~dB}$ of gain for the fluxgate action. The filtered signal (Fig. 6, bottom) was digitized at $10.0 \mathrm{ksps}$ and box-car average decimated to 100 sps before being telemetered to a computer for analysis.

\subsection{Noise floor characterization}

A known-amplitude sinusoidal $1 \mathrm{~Hz}$ magnetic test signal was applied to the solenoid inside the five-layer MuMETAL shield using a signal generator and a $10 \mathrm{k}$ low-tempco (temperature coefficient) resistor. The phasing of the direct digitization was adjusted to maximize the amplitude of the measured test signal. A linear scaling coefficient was then adjusted until the visualization software showed the test signal with the correct amplitude to calibrate the sensitivity of the complete single-axis magnetometer now formed around the fluxgate core under test. The $1 \mathrm{~Hz}$ test signal was then disabled, and $30 \mathrm{~min}$ of quiet data were taken with the core and sensor inside the magnetic shield. Welch's method of overlapped periodograms (100 sps, 4096-point fast Fourier transform (FFT), Hann window, $75 \%$ overlap) was used to 


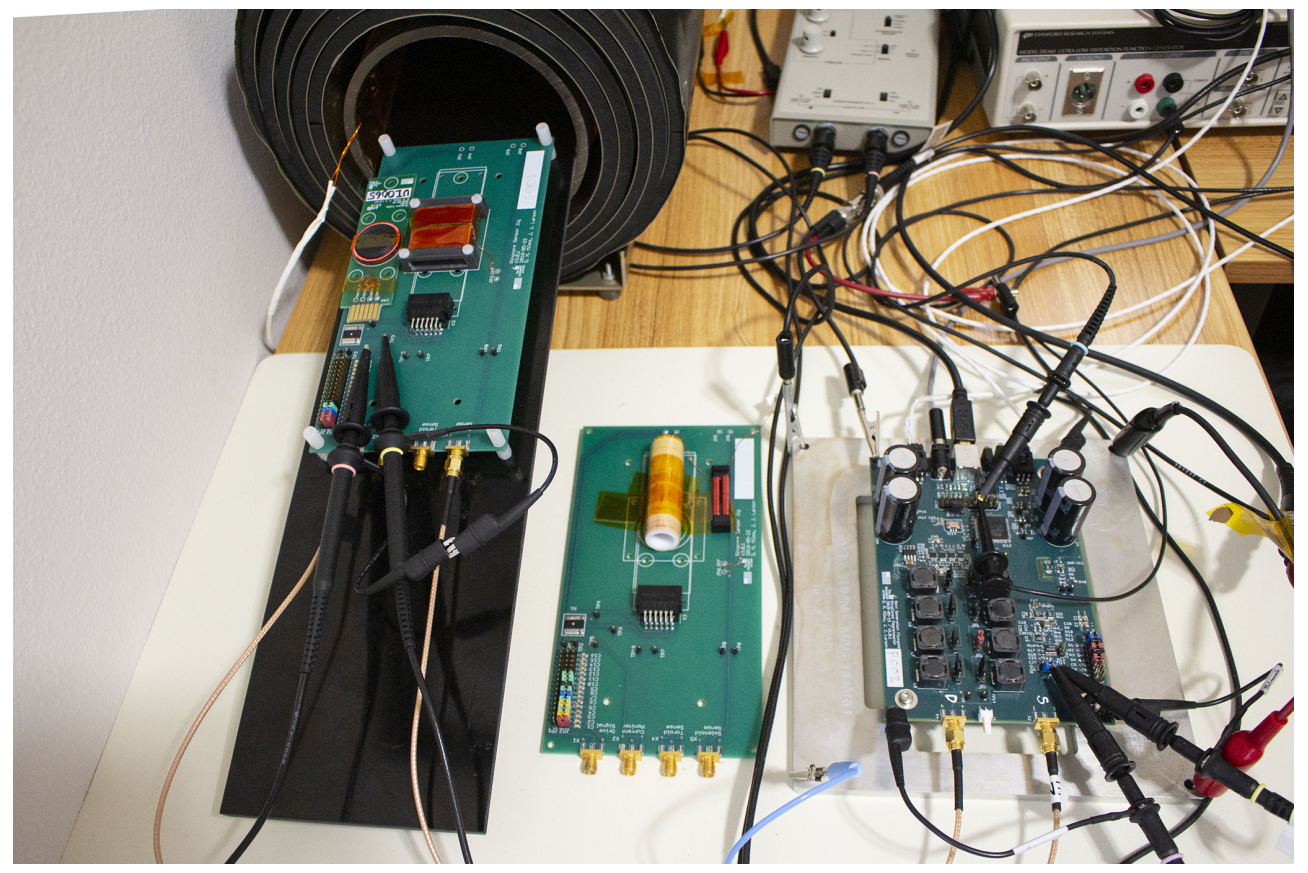

Figure 5. Experimental setup used to characterize core noise performance: five-layer MuMETAL shield with embedded solenoid, test fixtures for 1 in. ring and racetrack cores, and single-axis benchtop magnetometer electronics.

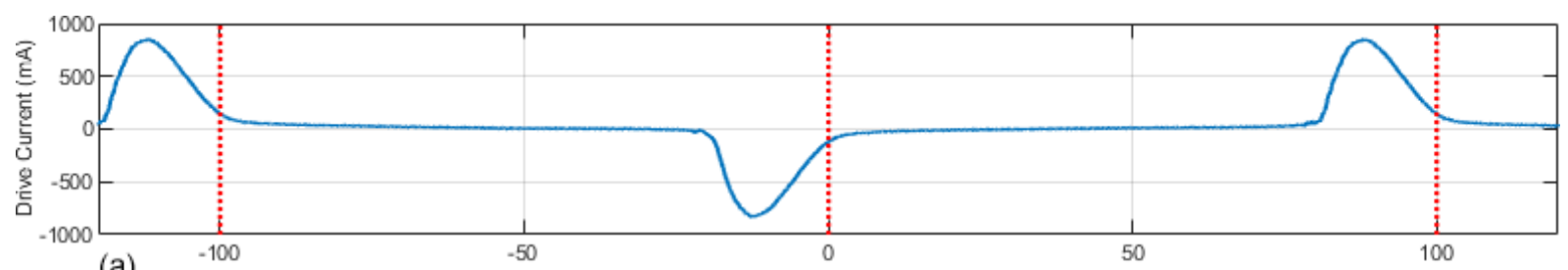

(a)

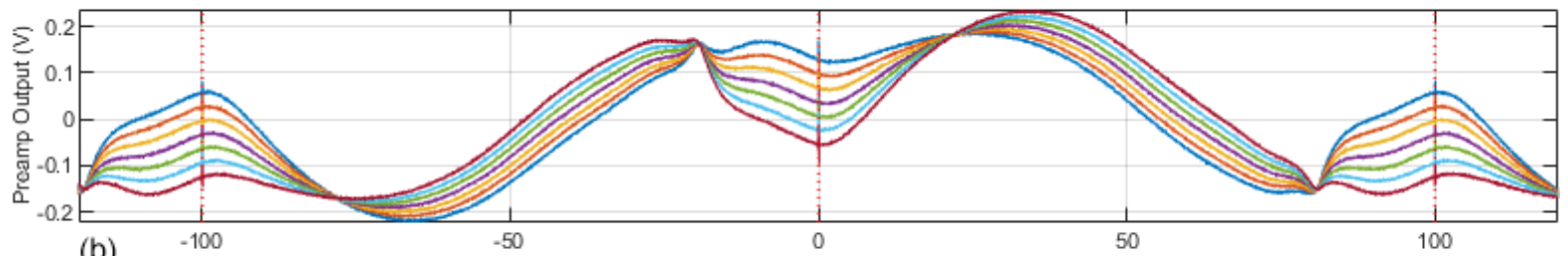

(b)

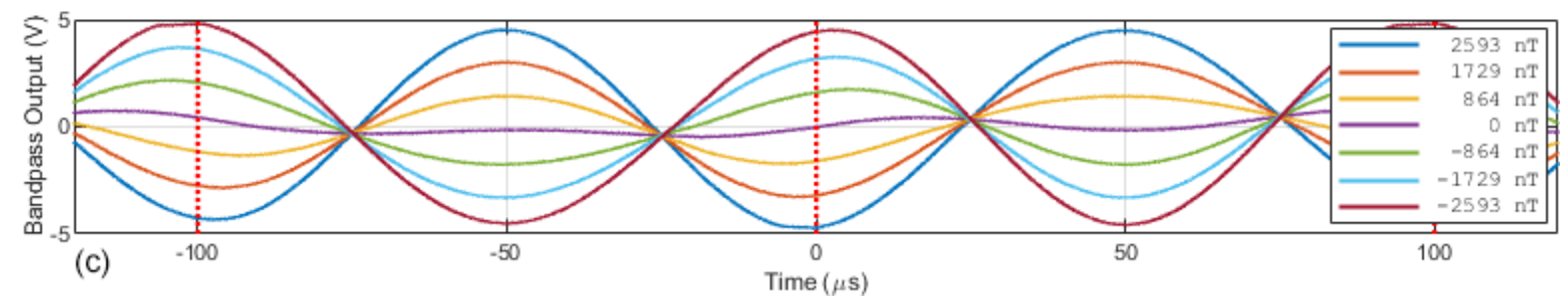

Figure 6. (a) Drive current periodically saturating the ring. (b) Output of the pre-amplifier. (c) Output of bandpass filter at $2 \mathrm{~F}$ frequency. Colors show modulation due to different applied fields. 

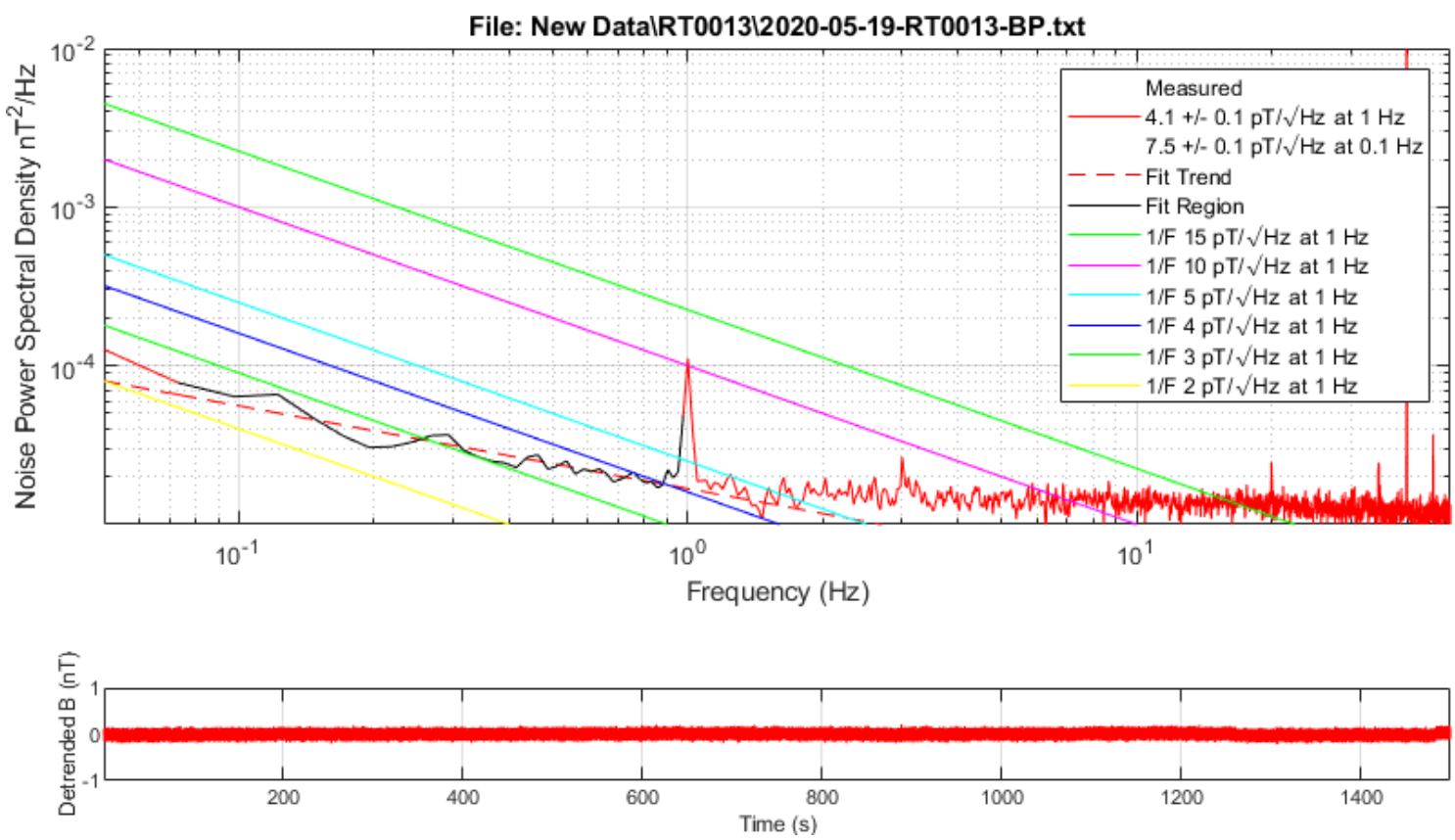

Figure 7. Example noise floor plot for core RT0013 $\left(6-81,50 \mu \mathrm{m}, 1150^{\circ} \mathrm{C}\right.$ dwell). Note that the noise trend below $\sim 1 \mathrm{~Hz}$ appears to be significantly below the expected $1 / \mathrm{F}$. The narrow-band feature $1 \mathrm{~Hz}$ is instrumental and related to 1 sps packetization and transmission over a USB interface.

estimate the power spectral density noise floor as shown in Fig. 7.

Two figures of merit were established to simplify comparing core performance. Robust linear regression (MATLAB robustfit) was used to fit a linear trend to the noise floor from 0.05 to $1.0 \mathrm{~Hz}$ to exclude local and instrumental narrow-band noise. This trendline was evaluated at $1 \mathrm{~Hz}$ to produce the standard $\mathrm{pT} / \sqrt{ } \mathrm{Hz}$ at $1 \mathrm{~Hz}$ noise metric. We also evaluated the trendline at $0.1 \mathrm{~Hz}$ to reflect the updated INTERMAGNET data requirement (Turbitt et al., 2013) for long period measurements, which has moved the noise requirement by a decade from $10 \mathrm{pT} / \sqrt{ } \mathrm{Hz}$ at $1 \mathrm{~Hz}$ to $10 \mathrm{pT} / \sqrt{ } \mathrm{Hz}$ at $0.1 \mathrm{~Hz}$. The narrow bandwidth feature in Fig. 7 is electronics noise related to data telemetry and is not relevant to the fluxgate core noise investigation.

This fitting technique provides a robust, quantitative estimate of the intrinsic magnetic noise of the core despite instrumental noise at $1 \mathrm{~Hz}$ due to telemetry and several intermittent narrow-band magnetic noise sources in the test environment. Figure 7 shows the noise floor for a racetrack core with a measured noise of $4.1 \pm 0.1 \mathrm{pT} / \sqrt{ } \mathrm{Hz}$ at $1 \mathrm{~Hz}$. It is interesting to note that the noise below $1 \mathrm{~Hz}$ seems to trend significantly below the historically referenced $1 / \mathrm{F}$ trend. This needs to be investigated further with a lower-noise pre-amplifier to exclude the possibility that the true trend is being masked by comparably high broadband digitizer noise.

\subsection{Power consumption characterization}

The drive circuit was powered by its own benchtop power supply allowing the $\pm 0.5 \mathrm{~mA}$ resolution of the power required to drive each core. The drive frequency, drive voltage, and series inductance were held constant for all tests. The capacitance required to achieve resonant drive was determined empirically as described above. Power consumption for each core was measured after each core had stabilized by operating for at least $60 \mathrm{~s}$.

\subsection{Grain size characterization}

Each heat treatment included $10 \mathrm{~mm} \times 10 \mathrm{~mm}$ coupons for each combination of metallurgy and foil thickness. These coupons were used to estimate the grain size of the heattreated material. Each coupon was photographed at $40 \times$ gain, with a graticule for scale, using a wide-field metallurgical inverted microscope under polarized visible light to emphasize the grain boundaries that had developed in the material as shown in Fig. 8a.

Grain size was estimated using the intercept method (Abrams, 1971) as implemented by the MATLAB linecut software package by Meister (2020). Lines are drawn across each sample and chord lengths are determined by eye each time a grain boundary is crossed. The distribution of chord lengths was fit to a log-normal curve (Fig. 8b) as

$y=\frac{A}{x a_{\sigma} \sqrt{2 \pi}} e^{\left(-\frac{\left(\log x-\log a_{\mu}\right)^{2}}{2\left(\log a_{\sigma}\right)^{2}}\right)}$. 
(a)
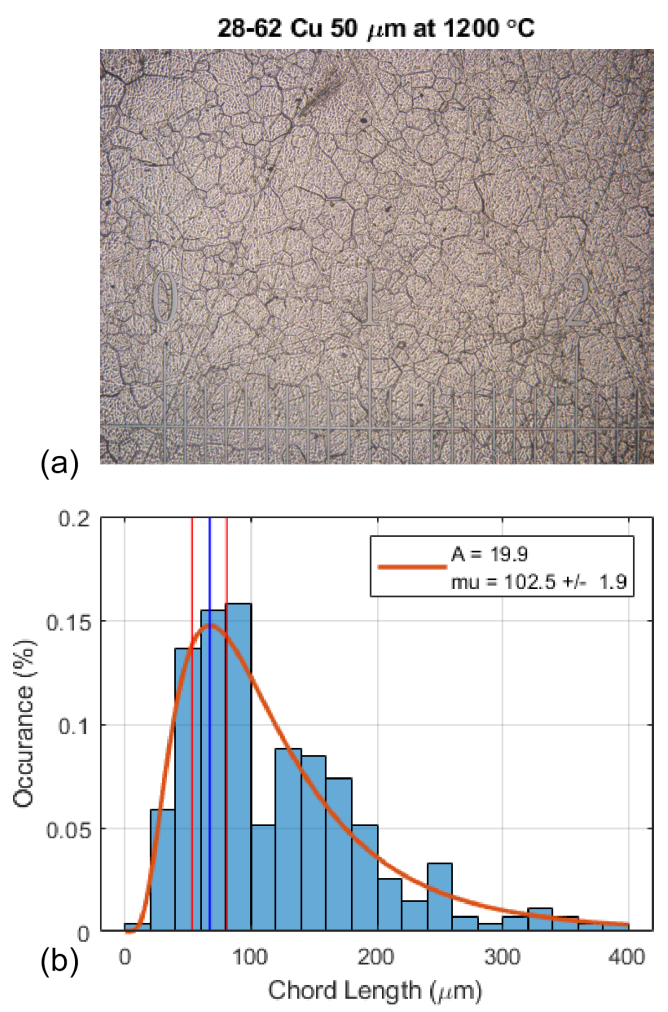

Figure 8. (a) Photograph of $50 \mu \mathrm{m}$ 6-81 Mo permalloy coupon heat treated at $1200^{\circ} \mathrm{C}$. Major increments in the graticule show $1 \mathrm{~mm}$ spacing. (b) Distribution of chord lengths (proxy for grain size) as determined visually using the intercept method.

For cross comparison, each distribution was characterized by the mode of its probability density function (vertical blue line) plus or minus $10 \%$ up and down from that point on the cumulative density function (vertical red lines). Appendix A contains images of all the coupons heat treatment as part of the optimization effort presented here.

\section{Results and discussion}

\subsection{Core performance}

Figure 9 summarizes the results of the parameter sweep of cores manufactured and tested for this experiment. The left column shows cores manufactured using the traditional $1 \mathrm{in}$. ring-core geometry, while the right column shows the new racetrack design. The first and second rows show the measured intrinsic magnetic noise of the cores at 1 and $0.1 \mathrm{~Hz}$, respectively. The third row estimates the grain size observed in the foil coupon using the mode of a log-normal fit to the measured chord size distribution (Fig. 12 below) plus or minus the $10 \%$ of the corresponding cumulative density function. Only a single foil coupon was manufactured for each alloy, thickness, and heat treatment but the data are shown in both columns for clarity. The bottom panel shows additional power required to drive each core. Green shows the 6-81 Mo alloy, while pink shows the new 28-62 Cu alloy. Finally, dashed lines indicate $100 \mu \mathrm{m}$ foil, while solid lines show $50 \mu \mathrm{m}$. The $100 \mu \mathrm{m} 28-62 \mathrm{Cu}$ racetrack core heat treated at $1250{ }^{\circ} \mathrm{C}$ dwell coupled large amounts of $1 \mathrm{~F}$ drive tone through the sensor saturating the pre-amplifier so its noise has been excluded.

Each point in Fig. 9 corresponds to a single fluxgate core and individual cores' performances are likely to vary similarly to the distribution shown in Fig. 2 of Narod (2014). Therefore, we expect significant variance in the individual data points in addition to the experimental uncertainty that is shown by the error bars. Overall trends in the data should be robust but individual data points should not be overinterpreted. Several trends are apparent.

The ring-core noise at $1 \mathrm{~Hz}$, noise at $0.1 \mathrm{~Hz}$, and power consumption varied more than the equivalent racetracks' performance. We cannot isolate the origin of this variation from the current dataset but speculate it may result from inconsistency in the welding process used to attach the spiral-wound foil in the $1 \mathrm{in}$. ring core or due to inadvertent welding when the complete $1 \mathrm{in}$. ring-core assembly is heat treated. Regardless, many of the same trends are observed in both the ringcore and racetrack data.

The 50 and $100 \mu \mathrm{m}$ foils produced broadly similar intrinsic magnetic noise. This was not expected since, as all the cores in Fig. 9 contain three layers, the $50 \mu \mathrm{m}$ cores contain half as much ferromagnetic material as the $100 \mu \mathrm{m}$ cores. Conversely, the lowest noise Infinetics rings known used a $12 \mu \mathrm{m}$ foil, so this may suggest $50 \mu \mathrm{m}$ is still above the optimum foil thickness.

The measured noise as a function of heat-treatment dwell temperature, for all rings, geometries, and frequencies, is generally concave upward with minima around $1150{ }^{\circ} \mathrm{C}$, suggesting this may be the local optimum. The $100 \mu \mathrm{m}$ foils require more power than the equivalent $50 \mu \mathrm{m}$ foils. In the racetrack geometry cores, the thicker foils require between 1.5 and 2 times more power. The ring cores show an equivalent trend in 6-81 Mo, while the $28-62 \mathrm{Cu}$ shows a much smaller effect. More generally, the racetrack cores require less power than their ring-core counterparts - despite containing more ferromagnetic material and generally providing lower noise. Both core designs have a comparable drive-winding resistance of 1.5-1.9 $\Omega$, so it seems possible that the power difference results from eddy current losses in the conductive Inconel Alloy X750 bobbin used in the 1 in. ring core that have no equivalent in the insulating plastic bobbins used in the racetrack cores.

Optical grain size analysis of the foil coupons showed a consistent pattern of larger grain size and larger spread with increasing heat treatment temperature in the $50 \mu \mathrm{m}$ foil consistent with accelerated grain growth at higher temperatures. The $100 \mu \mathrm{m}$ foil cores show a maximum in grain size at $\sim 1150^{\circ} \mathrm{C}$ dwell temperature but with wider variation. We speculate that the grains in the $100 \mu \mathrm{m}$ foil may not span the 

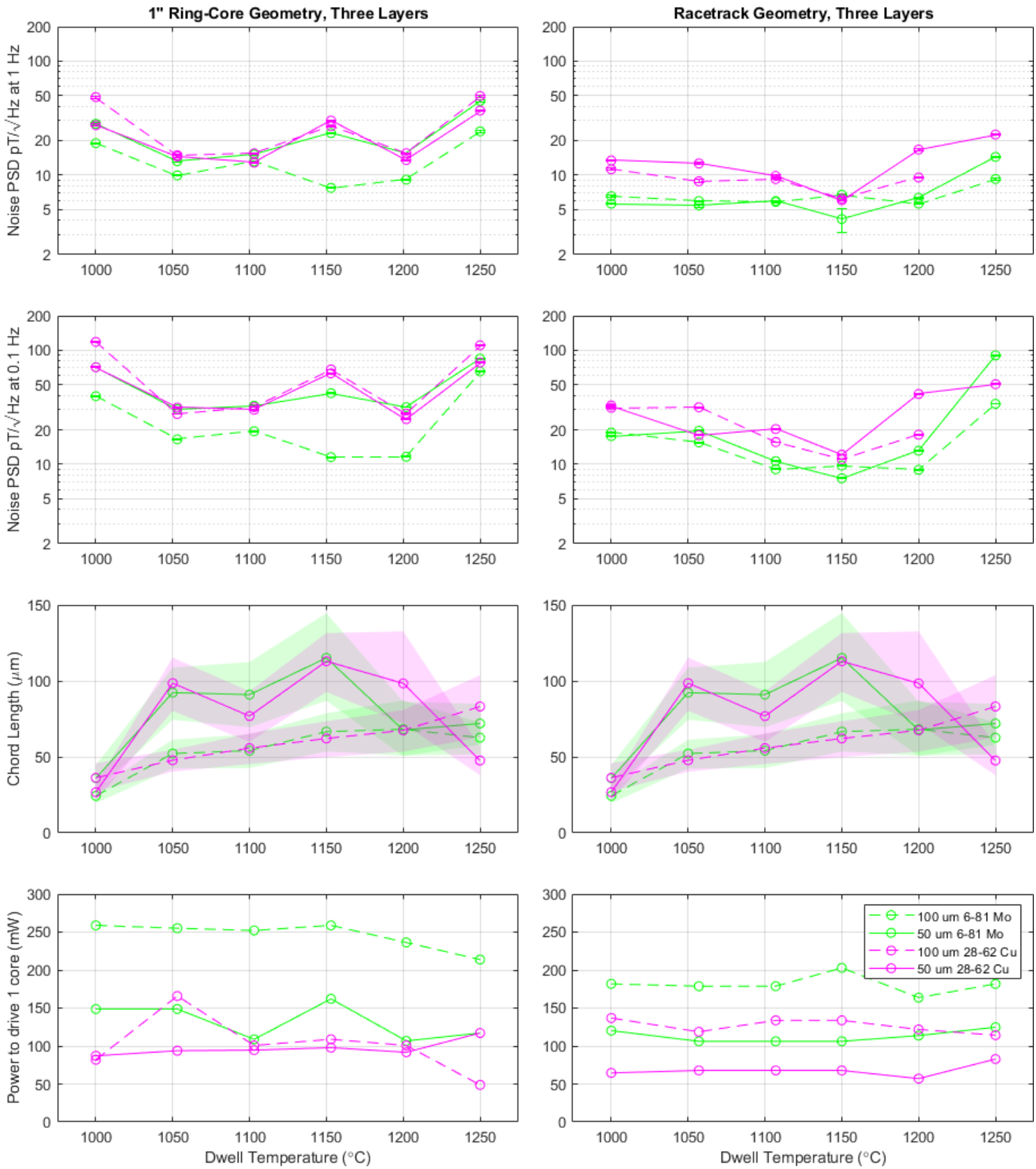

Figure 9. Left column shows 1 in. ring cores, while the right column shows racetrack cores. The rows show, top to bottom, noise at $1 \mathrm{~Hz}$, noise at $0.1 \mathrm{~Hz}$, chord length as a proxy for grain size (same data in both columns), and power required to drive each ring. All results are plotted against the dwell temperature used in their heat treatment.

entire thickness of the foil so the optical analysis of the surface is sampling various cross sections and providing less representative values. Couderchon et al. (1989) potentially saw a similar plateau in grain size.

The $28-62 \mathrm{Cu}$ material provides surprisingly respectable noise performance for a first attempt at a new alloy. Compared to the traditional $6-81 \mathrm{Mo}$ alloy, $28-62 \mathrm{Cu}$ provides noise performance ranging from equally to twice as noisy.
However, the power required to drive the $28-62 \mathrm{Cu}$ cores is roughly $30 \%$ lower than comparable 6-81 Mo cores.

The racetrack cores simultaneously provide lower noise and lower power consumption than their comparable ring core. The power advantage will be partially offset by the need for at least three racetrack cores per sensor, whereas only two are required for a double-wound ring-core sensor. 


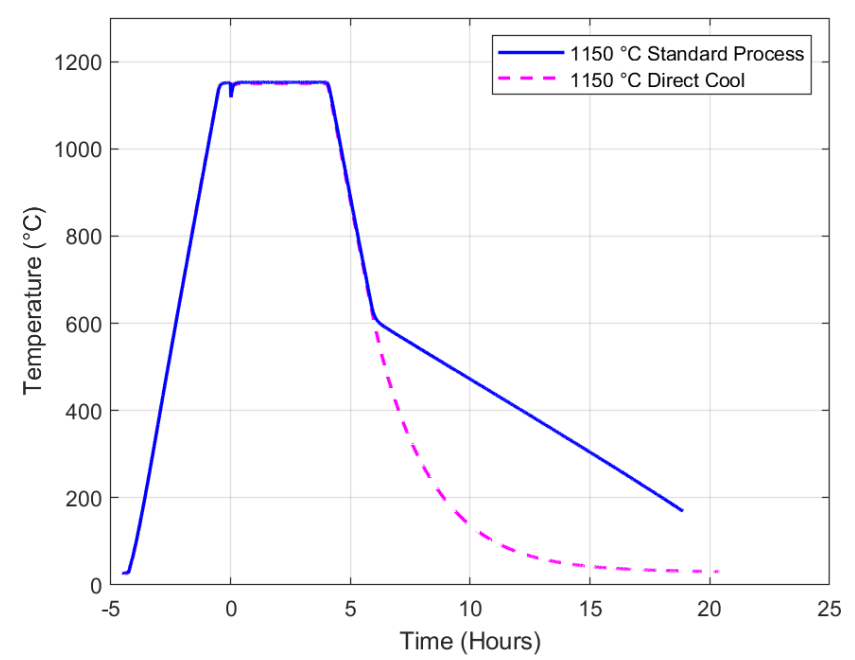

Figure 10. Standard heat treatment with slow post-disordering cool compared to direct cooling.

\subsection{Effect of the slow quench and sub-Curie heat treatment}

One heat treatment was accidently programmed to skip the second slow cool at $-35^{\circ} \mathrm{C}$ per hour ramp suggested by Gordon et al. (1968). Rather, the furnace attempted to ramp down to room temperature at $-300{ }^{\circ} \mathrm{C}$ per hour directly as shown in Fig. 10 - the actual ramp rate being slower and low temperatures due to the thermal mass of the furnace. This provided an opportunity to investigate the effect of this long tail in the heat treatment.

The two resulting ring cores (Fig. 11, dashed) had an average initial noise level of $\sim 13 \mathrm{pT} / \sqrt{ } \mathrm{Hz}$ at $1 \mathrm{~Hz}$. An equivalent set of five cores processed immediately beforehand (Fig. 11, solid) with the standard long-tail heat treatment had an average initial noise of $\sim 9 \mathrm{pT} / \sqrt{ } \mathrm{Hz}$ at $1 \mathrm{~Hz}$. Two additional heat treatments were executed to investigate whether this discrepancy was related to the cooling rate or simply time at elevated temperature below the Curie temperature. All seven rings were subjected to two rounds of an additional $100 \mathrm{~h}$ at $100^{\circ} \mathrm{C}$ described in Narod (2014). The initial $100 \mathrm{~h}$ at $100^{\circ} \mathrm{C}$ improved the noise floor of the five rings manufactured with the standard heat treatment by an average of $16 \%$, while the second $100 \mathrm{~h}$ at $100^{\circ} \mathrm{C}$ heat treatment provided no significant benefit. The two rings manufactured with the direct cool heat treatment showed no significant additional improvement from either $100 \mathrm{~h}$ at $100^{\circ} \mathrm{C}$ heat treatment.

\subsection{Grain size}

Figure 12 shows the distributions fitted to the chord (grain size) measurements for each alloy, foil thickness, and heat treatment. In general, hotter heat treatments increase the median chord length and broaden the distribution with $50 \mu \mathrm{m}$ $28-62 \mathrm{Cu}$ alloy showing the most consistent ordering. The

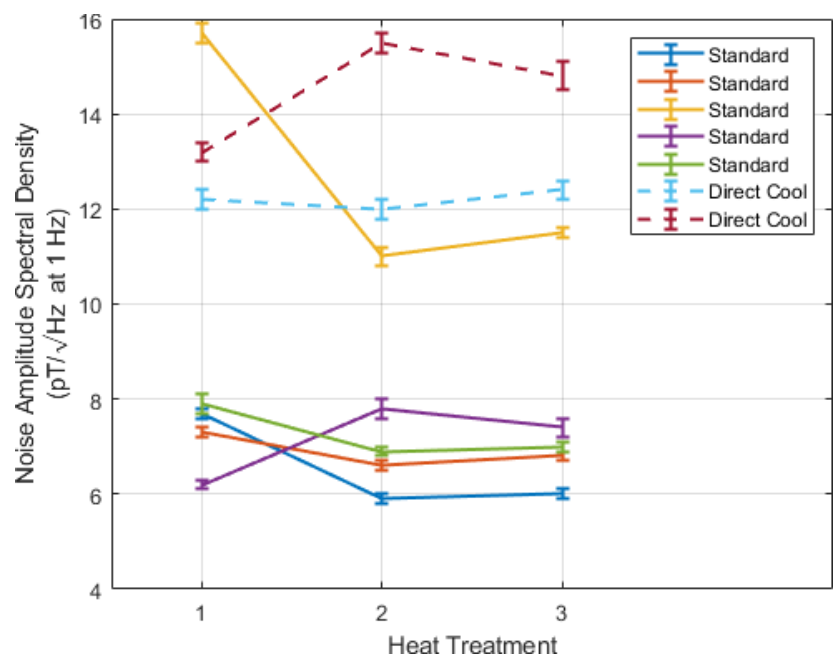

Figure 11. Comparison of ring cores manufactured with an initial standard heat treatment (solid) versus those with a direct cooling (dashed). Heat treatments 2 and 3 were each $100 \mathrm{~h}$ at $100^{\circ} \mathrm{C}$.

trend appears to break at the $1250^{\circ} \mathrm{C}$ temperature which corresponds (Fig. 9) to the increasing trend in magnetic noise. We hypothesize that higher soak temperatures lead to the formation of fewer primary recrystallization initiation sites, simply because there is less time available before the dislocation energy is consumed. Thus, there are fewer grains left after primary recrystallization.

\subsection{Effect of number of layers}

A batch of four racetrack cores were manufactured to explore the relationship between magnetic noise, power consumption, and the number of foil layers. The four cores contained 1, 2, 6, and 9 layers of $50 \mu \mathrm{m} 28-62 \mathrm{Cu}$ alloy and had a common heat treatment. Figure 13 shows that increasing the number of foil layers decreases the magnetic noise at 0.1 and $1.0 \mathrm{~Hz}$ with the effect diminishing between six and nine layers. Power consumption increases linearly with the number of layers.

\subsection{Noise distribution}

We manufactured 20 notionally identical racetrack cores to test the noise variability of the manufacturing process. As before, all cores were three layers of $50 \mu \mathrm{m} 28-62$ foil heat treated with a dwell temperature of $1150^{\circ} \mathrm{C}$. Figure 14 shows a histogram of the noise floor distributions showing peaks at $\sim 16 \mathrm{pT} / \sqrt{ } \mathrm{Hz}$ at $0.1 \mathrm{~Hz}$ and $9 \mathrm{pT} / \sqrt{ } \mathrm{Hz}$ at $1 \mathrm{~Hz}$.

\section{Conclusions}

The racetrack washer design seems to offer several advantages over the traditional $1 \mathrm{in}$. spiral-wound ring core: more consistent yield in noise performance, significantly fewer 

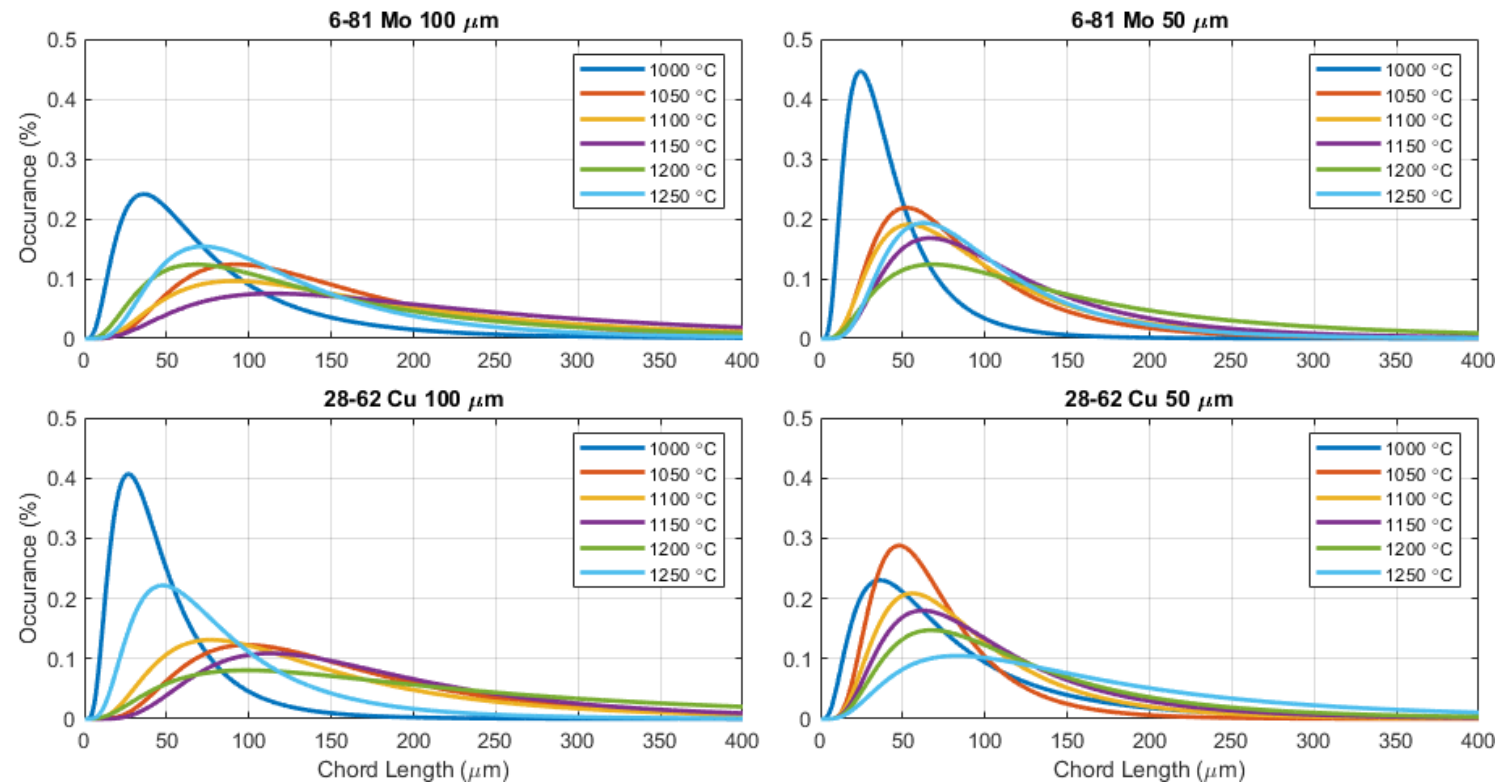

Figure 12. Chord-size histograms for each material and thickness showing the effect of heat-treatment temperature on grain size.

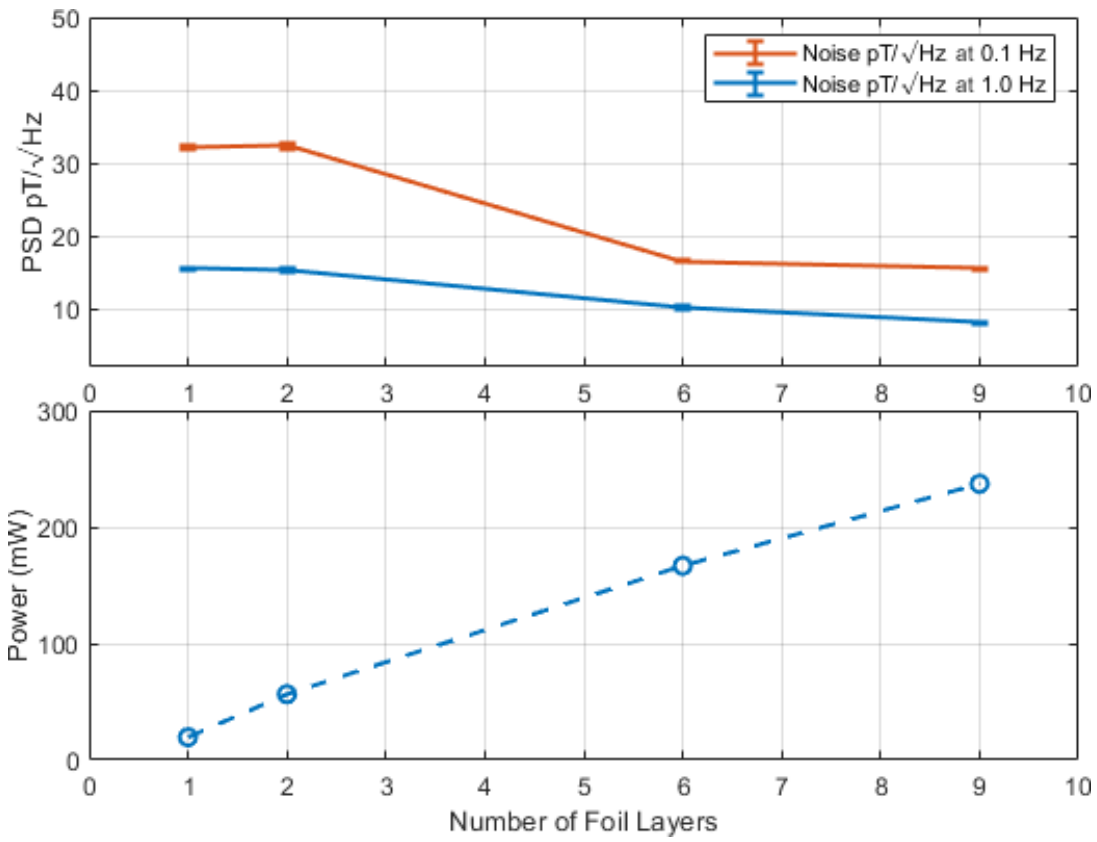

Figure 13. Magnetic noise and power consumption as a function of number of foil layers.

high-noise outliers, and lower noise performance at equal or lower power consumption per core. These advantages will be partially offset by the need for at least one core per measurement axis (three cores per sensor), whereas ring cores can be double wound (two cores per sensor). In general, the $50 \mu \mathrm{m}$ foils outperform the $100 \mu \mathrm{m}$ foils in terms of noise per drive power.

In this paper, we have introduced a novel, low-noise and low-power nickel alloy we have designated $28-62 \mathrm{Cu}$ permal- loy. It comprises, by weight, $28 \% \mathrm{Cu}, 62 \% \mathrm{Ni}$, Fe balance. This alloy is suggested by data published in von Auwers and Neumann (1935) and theory in Narod (2014). In 1935, high$\mathrm{Cu}$-content permalloys were investigated for more typical, high-saturation induction applications and fell out of favor. We believe that we are the first investigators since then to revisit $\mathrm{Cu}$ permalloys and specifically with regard to fluxgate sensors where lower saturation induction is advantageous. 


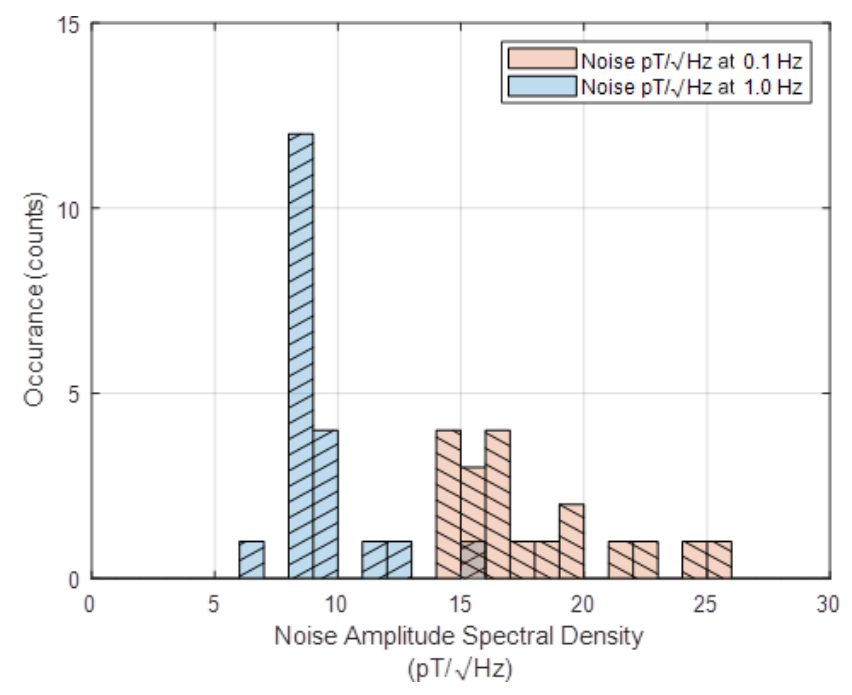

Figure 14. Histograms of noise distribution for 20 cores. Bin $16 \mathrm{pT} / \sqrt{ } \mathrm{Hz}$ includes cores from both histograms.

The 6-81 Mo alloy generally produces lower noise than the 28-62 $\mathrm{Cu}$ alloy, all other variables held equal. However, the 28-62 requires significantly lower power. The consistent grain size and evolution shown by the $50 \mu \mathrm{m}$ coupon suggests that the grains developed in the foil may be spanning the entire thickness of the foil, whereas in the $100 \mu \mathrm{m}$ foils the grains may not penetrate the complete thickness. The $1150^{\circ} \mathrm{C}$ dwell temperature appears to provide the lowest noise for all alloy and foil thickness combinations. Directly cooling at $300^{\circ} \mathrm{C}$ per hour down to room temperature appears to significantly degrade noise performance in a way that cannot be improved by subsequent sub-Curie heat treatment. However, the $100 \mathrm{~h}$ at $100^{\circ} \mathrm{C}$ sub-Curie secondary heat treatment offers a significant improvement in cores manufactured using the standard process suggesting it be added to the standard process or the second cooling rate be decreased. Additional layers of foil appear to reduce the magnetic noise until approximately six to nine layers. Each additional foil layer causes a linear increase in the power consumption.

\section{Future work}

These results suggest that thinner foils may yield superior noise and power performance which is consistent with $12.5 \mu \mathrm{m}$ foil used in the best historical Infinetics cores. We are currently developing improved rolling mill capacity with the intention of investigating 25 and $12.5 \mu \mathrm{m}$ foils. In general, a racetrack geometry core containing more layers of thinner copper alloy foil seems like a promising path to consistently manufacturable, low-noise and low-power fluxgate cores. Alloy 28-62 $\mathrm{Cu}$ was chosen as the first copper alloy trial due to it having magnetic properties similar to those of 6-81 Mo in the molybdenum permalloy composition range (Pfeifer and Boll, 1969). 28-62 Cu has approximately zero magnetostriction and has minimum magnetocrystalline anisotropy, as evidenced by its local maximum initial permeability and minimum coercivity, with all these properties achieved by identical heat treatment.

The test of the alloy $28-62 \mathrm{Cu}$ was a preliminary study. Based on these results, we have begun an extensive survey of alloys of nearby compositions, guided by magnetic properties data presented in von Auwers and Neumann (1935). We plan to cover a composition range from $28 \%$ to $51 \%$ copper and covering the zero magnetostriction range. We will be examining DC resistivity, coercivity, saturation moment, initial and maximum differential permeability, magnetostriction, Curie temperature, grain size, and grain growth fabrics with some of these properties examined at temperatures from room temperature to Curie temperature. 


\section{Appendix A: Grain photos}

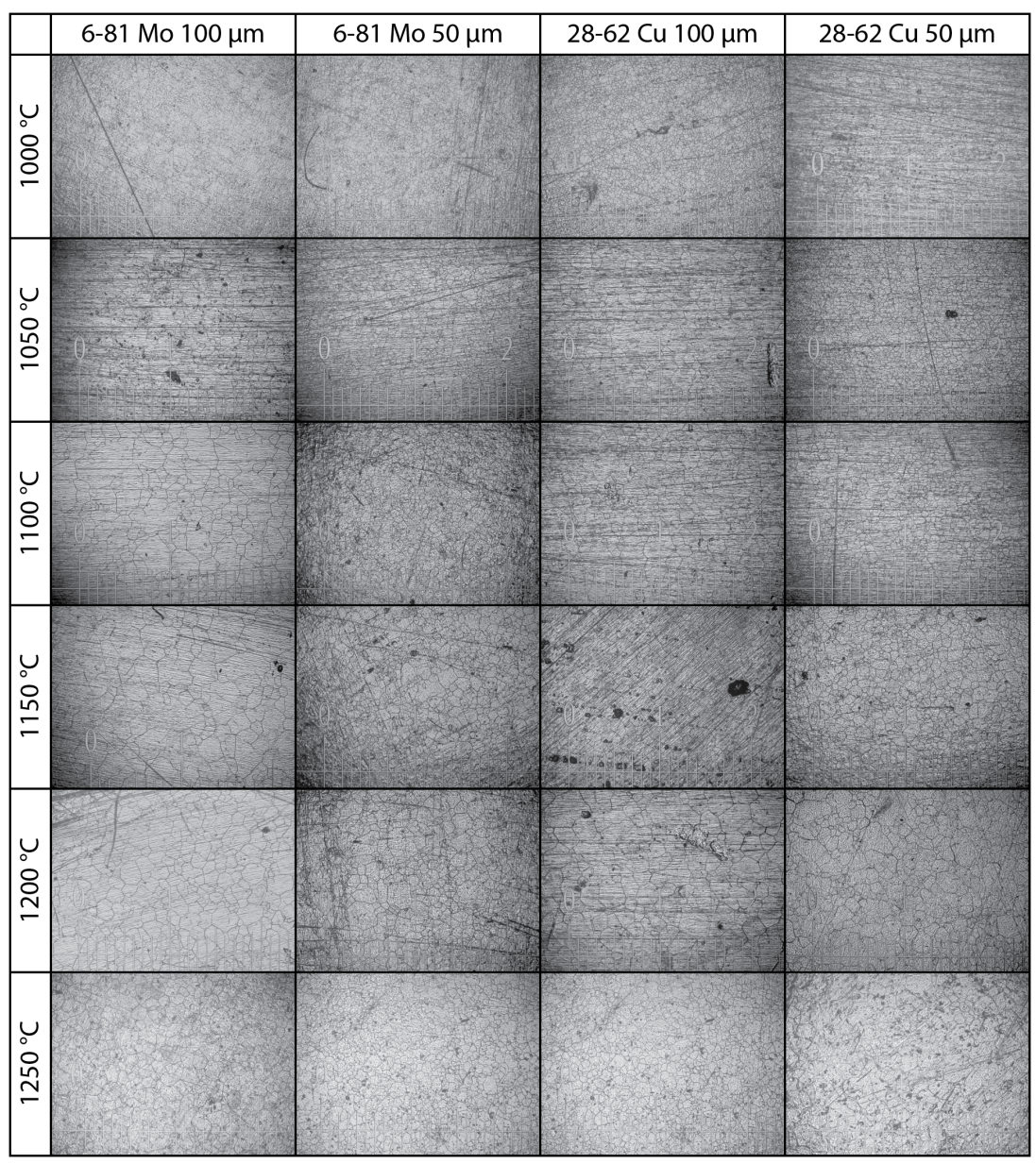

Figure A1. Photographs of each coupon showing grain size. Major ticks in the graticules show $1 \mathrm{~mm}$ spacing. 

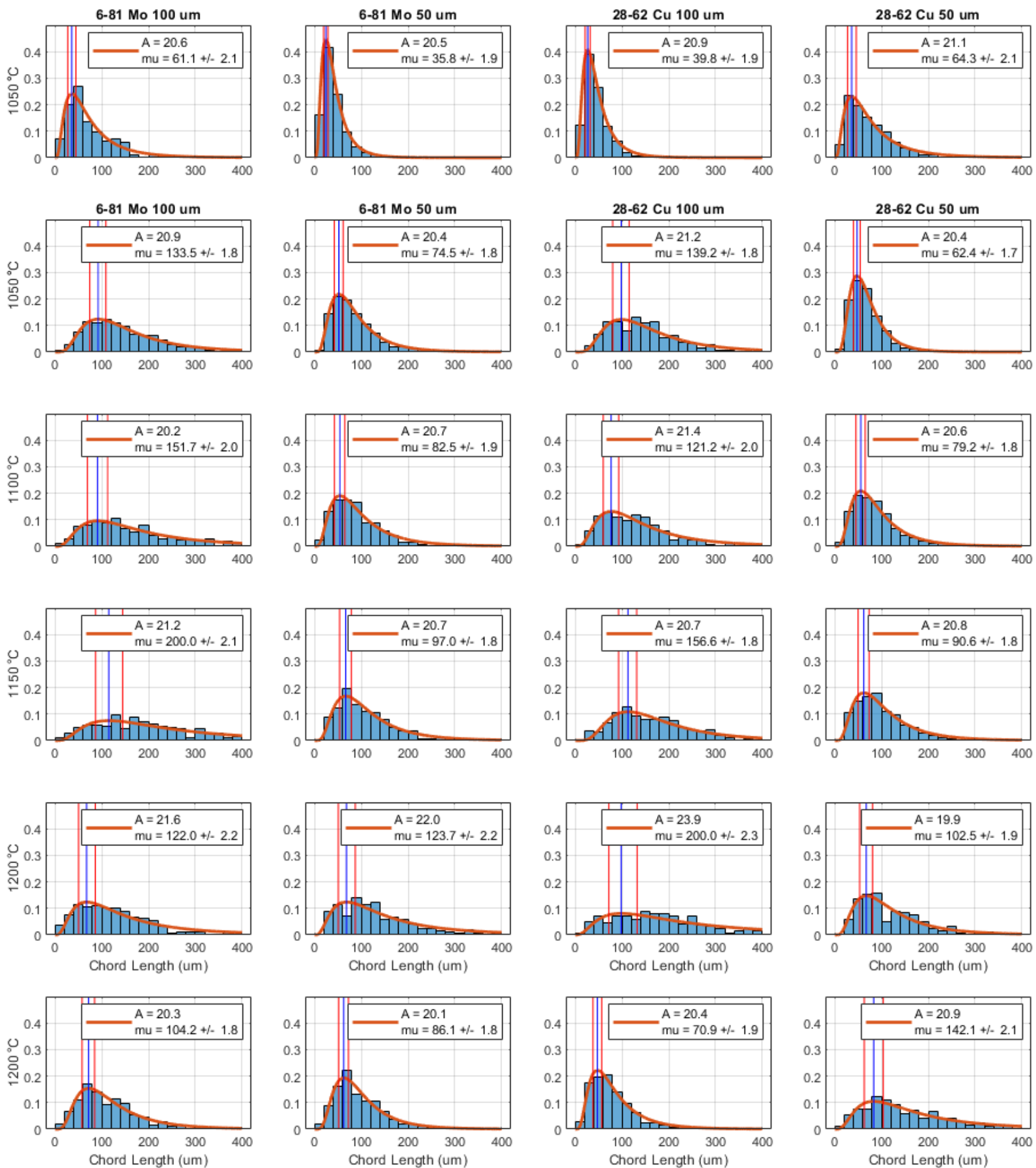

Figure A2. Chord-size distribution for each foil coupon. 
Code and data availability. Data and source code used in the creation of this paper can be accessed by contacting the authors.

Author contributions. DMM wrote the manuscript with contributions from all authors. RD led the design of the heat-treatment furnace used to manufacture the cores described here. KG assisted with the characterization of the experimental fluxgate cores. CTH led the development and manufacture of the racetrack core design. $\mathrm{BBN}$ provided the underlying theory of the new copper alloy and the scientific interpretation of the relation between grain structure and magnetic noise. MDW assisted with core manufacturing and imaged the foil coupons.

Competing interests. B. Barry Narod operated Narod Geophysics Ltd., which manufactured fluxgate magnetometers until the company ceased production operation in 2008. David M. Miles and B. Barry Narod hold provisional US patent $63 / 164,045$ related to the use of the described copper alloy regime for magnetic field instruments and magnetic shielding.

Disclaimer. Publisher's note: Copernicus Publications remains neutral with regard to jurisdictional claims in published maps and institutional affiliations.

Financial support. This research has been supported by the National Aeronautics and Space Administration (grant no. 80NSSC19K0491) and the National Aeronautics and Space Administration (grant no. 80GSFC18C0008).

Review statement. This paper was edited by Valery Korepanov and reviewed by Dave Sheppard and one anonymous referee.

\section{References}

Abrams, H.: Grain size measurement by the intercept method, Metallography, 4, 59-78, https://doi.org/10.1016/00260800(71)90005-X, 1971.

Couderchon, G., Porteseil, J. L., Bertotti, G., Fiorillo, F., and Soardo, G. P.: Magnetization process in NiFe alloys with vanishing anisotropies, IEEE T. Magn., 25, 3973-3975, 1989.

English, A. T. and Chin, G. Y.: Metallurgy and magnetic properties control in permalloy, J. Appl. Phys., 38, 1183-1187, 1967.

Fornacon, K.-H., Auster, H. U., Georgescu, E., Baumjohann, W., Glassmeier, K.-H., Haerendel, G., Rustenbach, J., and Dunlop, M.: The magnetic field experiment onboard Equator-S and its scientific possibilities, Ann. Geophys., 17, 1521-1527, https://doi.org/10.1007/s00585-999-1521-3, 1999.

Gordon, D., Lundsten, R., and Chiarodo, R.: Factors affecting the sensitivity of gamma-level ringcore magnetometers, IEEE T. Magn., 1, 330-337, https://doi.org/10.1109/TMAG.1965.1062987, 1965.
Gordon, D., Lundsten, R., Chiarodo, R., and Helms, H.: A fluxgate sensor of high stability for low field magnetometry, IEEE T. Magn., 4, 397-401, 1968.

Hinnrichs, C., Pels, C., and Schilling, M.: Noise and linearity of a fluxgate magnetometer in racetrack geometry, J. Appl. Phys., 87, 7085-7087, https://doi.org/10.1063/1.372939, 2000.

Hinnrichs, C., Stahl, J., Kuchenbrandt, K., and Schilling, M.: Dependence of sensitivity and noise of fluxgate sensors on racetrack geometry, IEEE T. Magn., 37, 1983-1985, https://doi.org/10.1109/20.951028, 2001.

Janosek, M.: Parallel Fluxgate Magnetometers, in: High Sensitivity Magnetometers, edited by: Grosz, A., Haji-Sheikh, M. J., and Mukhopadhyay, S. C., Springer International Publishing, Cham, 41-61, https://doi.org/10.1007/978-3-319-34070-8_2, 2017.

Meister, S.: grain and particle analysis with line intersection method, MATLAB Central File Exchange, https://www.mathworks.com/matlabcentral/fileexchange/ 35203-grain-and-particle-analysis-with-line-intersection-method (last access: 1 March 2022), 2020.

Miles, D. M., Ciurzynski, M., Barona, D., Narod, B. B., Bennest, J. R., Kale, A., Lessard, M., Milling, D. K., Larson, J., and Mann, I. R.: Low-noise permalloy ring cores for fluxgate magnetometers, Geosci. Instrum. Method. Data Syst., 8, 227-240, https://doi.org/10.5194/gi-8-227-2019, 2019.

Moldovanu, C., Brauer, P., Nielsen, O. V., and Petersen, J. R.: The noise of the Vacquier type sensors referred to changes of the sensor geometrical dimensions, Sensor. Actuat. A-Phys., 81, 197199, https://doi.org/10.1016/S0924-4247(99)00087-4, 2000.

Müller, M., Lederer, T., Fornacon, K. H., and Schäfer, R.: Grain structure, coercivity and high-frequency noise in soft magnetic Fe-81Ni-6Mo alloys, J. Magn. Magn. Mater., 177, 231-232, 1998.

Musmann, G.: Fluxgate magnetometers for space research, BoDBooks on Demand, 2010.

Narod, B. B.: The origin of noise and magnetic hysteresis in crystalline permalloy ring-core fluxgate sensors, Geosci. Instrum. Method. Data Syst., 3, 201-210, https://doi.org/10.5194/gi-3201-2014, 2014.

Narod, B. B., Bennest, J. R., Strom-Olsen, J. O., Nezil, F., and Dunlap, R. A.: An evaluation of the noise performance of Fe, Co, $\mathrm{Si}$, and $\mathrm{B}$ amorphous alloys in ring-core fluxgate magnetometers, Can. J. Phys., 63, 1468-1472, 1985.

Odani, Y.: Magnetic Properties of Cube-Textured 6-81.3 Mo Permalloy, J. Appl. Phys., 35, 865-866, 1964.

Pfeifer, F.: Zum Verständnis der magnetischen Eigenschaften technischer Permalloylegierungen, Z. Met., 57, 295, 1966.

Pfeifer, F. and Boll, R.: New soft magnetic alloys for applications in modern electrotechnics and electronics, IEEE T. Magn., 5, 365370, 1969.

Primdahl, F.: The fluxgate magnetometer, J. Phys. E Sci. Instrum., $12,241,1979$.

Ripka, P.: Improved fluxgate for compasses and position sensors, J. Magn. Magn. Mater., 83, 543-544, https://doi.org/10.1016/03048853(90)90618-Z, 1990.

Ripka, P.: Race-track fluxgate sensors, Sensor. Actuat. A-Phys., 37-38, 417-421, https://doi.org/10.1016/0924-4247(93)80071N, 1993. 
Ripka, P.: Race-track fluxgate with adjustable feedthrough, Sensor. Actuat. A-Phys., 85, 227-231, https://doi.org/10.1016/S09244247(00)00394-0, 2000.

Scanlon, W. W.: Solid state research of the Applied Physics Department for the year 1965, Naval Ordnance Lab, White Oak, MD, 1966.

Scarzello, J. F., Holmes, J. J., and O'keefe, E. C.: Integrating fluxgate magnetometer, US Department of Navy, United States patent US 6,278,272, 2001.

Sene, F. F. and Motta, C. C.: Synthesis and characterization of Ni-Mo filler brazing alloy for Mo-W joining for microwave tube technology, Mater. Res., 16, 417-423, https://doi.org/10.1590/S1516-14392013005000019, 2013.

Snare, R. C.: A History of Vector Magnetometry in Space, in: Measurement Techniques in Space Plasmas Fields, edited by: Pfaff, R. F., Borovsky, J. E., and Young, D. T., American Geophysical Union, 101-114, https://doi.org/10.1002/9781118664391.ch12, 1998.
Turbitt, C., Matzka, J., Rasson, J., St-Louis, B., and Stewart, D.: An instrument performance and data quality standard for intermagnet one-second data exchange, in: Proceedings of the XVth IAGA Workshop on Geomagnetic Observatory Instruments, Data Acquisition, and Processing, XVth IAGA Workshop on Geomagnetic Observatory Instruments and Data Processing, 4-14 June 2012, Cadiz, Spain, 186-188, 2013.

von Auwers, O. and Neumann, H.: Über Eisen-Nickel-KupferLegierungen hoher Anfangspermeabilität, Spec. Print. Sci. Publ. Siemens-Fact., XIV, 92-108, 1935.

Wallis, D. D., Miles, D. M., Narod, B. B., Bennest, J. R., Murphy, K. R., Mann, I. R., and Yau, A. W.: The CASSIOPE/e-POP Magnetic Field Instrument (MGF), Space Sci. Rev., 189, 27-39, https://doi.org/10.1007/s11214-014-0105-z, 2015. 